ORIGINAL ARTICLE

\title{
Orthodontic Principles and Practice based Knowledge and Attitude among general dental practitioners
}

\author{
SHOAIB MASOOD ${ }^{1}, \mathrm{CH}$. REHAN QAMAR ${ }^{2}$, FAREEHA AMDAD ${ }^{3}$, MUHAMMAD HASSAN ${ }^{4}$, AMINA TARIQ $^{5}$ \\ ${ }_{1}^{1}$ Postgraduate Resident, Department of Orthodontics, University College of Medicine \& Dentistry, University of Lahore. \\ ${ }^{2}$ Professor, Department of Orthodontics, University College of Medicine \& Dentistry, University of Lahore \\ ${ }^{3}$ General Dentist, University College of Medicine \& Dentistry, University of Lahore \\ ${ }^{4}$ Associate Professor of Science of Dental Materials, University College of Medicine \& Dentistry, University of Lahore \\ ${ }^{5}$ Postgraduate research coordinator, University College of Medicine \& Dentistry, University of Lahore \\ Correspondence to Dr. Shoaib Masood, Email ID:shoaibsahibzada911@hotmail.com
}

\begin{abstract}
Background: This study was formulated for the comparative evaluation of the knowledge and attitude of the general dental practitioners and non-orthodontic specialties about the orthodontic treatment.

Methodology: Data of this cross sectional study was collected from 100 general dentists between an age ranges of 30 to 50 years using simple random sampling from all over Lahore.

Results: The percentage for the positive responses was $85.69 \%$ whereas the negative response rate was very low which was reported as $14.3 \%$. This showed that dental practitioners in market are practicing orthodonticskills. The response rate of general practitioners was: $60.42 \%$ positive responses and $39.57 \%$ negative responses were obtained which showed that more than half of general dental practitioners have a positive attitude towards orthodontic treatment guidance to their patients with general complaints.

Conclusion: The overall attitude of general dental practitioners is satisfactory towards orthodontic treatment in general patients. Moreover, dental practitioners in Pakistan are were well aware of the Skills used before, during and after the orthodontic treatment.

Keywords: Clinical practice, Knowledge, Orthodontic treatment, Dental Practitioners
\end{abstract}

\section{INTRODUCTION}

General dentistry is often the first line of defense for the oral health and hygiene of a person. Good oral health has a positive impact on the development, well-being, education, and self-esteem of an individual. Heightened knowledge and promising attitude of a general dentist is paramount in providing effective oral health care to the community. ${ }^{1}$ One of the most common etiologies for the development of dental caries, fluorosis, temporomandibular disorders and gingival disease is malocclusion ${ }^{2}$ which is treated under orthodontic procedures.Orthodontic treatment results in improved stomatognathic function,better esthetics and prevention of tissue damage ${ }^{3}$. Other important benefits are improved quality of life, increased self-confidence, physical and psychological changes ${ }^{4,5}$.

Building and promoting awareness with regards to the maloculated teeth, problems and orthodontic solutions in public is a multidisciplinary affair which could be sorted out if general dental practitioners and other non-orthodontic specialties becomes effective mediators in conveying the importance of orthodontic treatment to masses ${ }^{6}$. Good knowledge and attitude of principles and practice of orthodontic treatment are the only standards to fulfill the mediating requirements. Therefore, there is a dire need, especially, in developing countries, to assess and quantify the knowledge and attitude of dental practitioners towards orthodontics, in order to provide awareness and quality health care to the public ${ }^{7}$. This study was formulated for the comparative evaluation of the knowledge and attitude of the general dental practitioners and non-orthodontic specialties about the orthodontic treatment.

Received on 15-02-2021

Accepted on 27-06-2021

\section{MATERIAL AND METHODS}

Research design: This quantitative study was of crossectional nature as the sample was a representative subset of the population in a specific point of time.

Sampling and Sample size: Random sampling was used to collect data from dental practitioners. Sample size was 100 participants which was calculated by using Gpower calculation software.

Inclusion criteria: General dental practitioner with bachelor degree and dentist with post-graduation degree in any branch (non-orthodontic Specialty) with age ranging between 30 to 50 years were the participants of the study.

Exclusion criteria: Freshly pass-out dentists were not taken as participants of the study. Dentists with age more than 50 years and general dental practitioners, who stopped their practice were not inducted in the study.

Procedure: The study was done on 100 dentists of age ranges between 30 and 50 years, which were divided into two groups. These were selected from various regions of the Lahore, to study the knowledge and attitude toward principles and practice of orthodontic treatment.The dentists were contacted personally and were handed over the questioner, which was duly collected after two days. Brief information about the purpose of study was given to all participants through personal contact via phone as well as through email, and the informed consent was obtained from each participantas voluntary participant in the study.

Instruments: Structured questionnaire containing 21 questions was developed particularly for this study. The questionnaire was formulated to evaluate the knowledge and attitude toward practice of orthodontic treatment among general dental practitioners and non-orthodontic specialties. The questionnaire had two sub-scales named 
as Skill based questionnaire and Attitude based questionnaire for orthodontic practice.

Knowledgeevaluation questionnaire for orthodontic practice: It contained 13 questions which were formulated to study the knowledge and skills amonggeneral dental surgeons and non-orthodontics specialties about orthodontic practices. The questions havedichotomous type of response generation, i-e."Yes" or "No" and each correct answer were given a Score 1 and incorrect answer was given score zero. The questions were designed to measure the knowledge regarding starting age of orthodontic treatment, mixed orthodontic treatment in mixed dentition stage, facial appearance, functional therapy, proclined teeth, extraction of teeth for orthodontic purpose, habits, anchorage and retainers.

Attitude evaluation questionnaire for orthodontic practice: In this section, 06 questions were prepared, which also have dichotomous response options, i.e.,"Yes" or "No" and scoring was done by considering 1 for correct answer and zero for the wrong answer. In this the questions were formulated to study attitude toward orthodontic treatment like, diagnostic orthodontic procedures, opinion of orthodontist, giving information to patient about malocclusion when patient comes for the other dental treatment, orthodontic treatment in patients with periodontal problems, orthognathic surgeries and orthodontic treatment in missing teeth.

Ethical consideration: Ethical considerations included research information sharing with participants before inviting them as participants for the research, taking writing consent, maintaining confidentiality of data and keeping the participants' identity anonymous in the research procedure and reporting the results. For research information sharing, research information sheet was developed and shared with the participants which contained the purpose of the research and the contact details of the researcher. The right of leaving the research at any point by the participants was reported. Consent forms were get signed by the participants before response recording. The questionnaire booklets were coded by numbers instead of the names of the participants to maintain the anonymity of the data. Confidentiality was maintained by keeping the data between researchers.

\section{RESULT}

The results of the study revealed that the awareness among the dental practitioners regarding pathologies treatments before orthodontic treatment was higher i-e: $(97 \%)$. In response to the treatment age specificity $60 \%$ dental practitioners agree to the statement whereas $40 \%$ denied. According to $97 \%$ dental practitioners, orthodontic treatment improves smile, speech and oral hygiene of the patients. It was found that $100 \%$ dental practitioners reported effect of paranormal habits on teeth. $97 \%$ dental practitioners were found to have awareness of differences between dental and skeletal malocclusion. The response rate for enforced extraction in every caseduring orthodontic treatment was $4 \%$ agreement to the statement which showed extraction is not obligatory part of orthodontic treatment in all cases. 92\% dental practitioners agreed upon the usefulness of orthodontic treatment for TMJ disorders. Space maintainers were found to be the part of dental practice among $79 \%$ dental practitioners according to requirement of treatment. $96 \%$ dental practitioners were found to have awareness of functional appliance therapy whereas $97 \%$ dental practitioners were aware of the positive role of functional appliance therapy in orthodontic treatment. With regards to the usage of mini screws for anchorage during orthodontic treatment, the results revealed $97 \%$ awareness level among dental practitioners. High Response rate on consideration of appropriate molar relationship and interdigitation after orthodontic treatment was reported, i.e., $98 \%$. 100\% practitioners reported that retainers will be worn after fixed appliance therapy.

Graph 1: Knowledge evaluation among dental practitioners with regards to Orthodontic treatment.

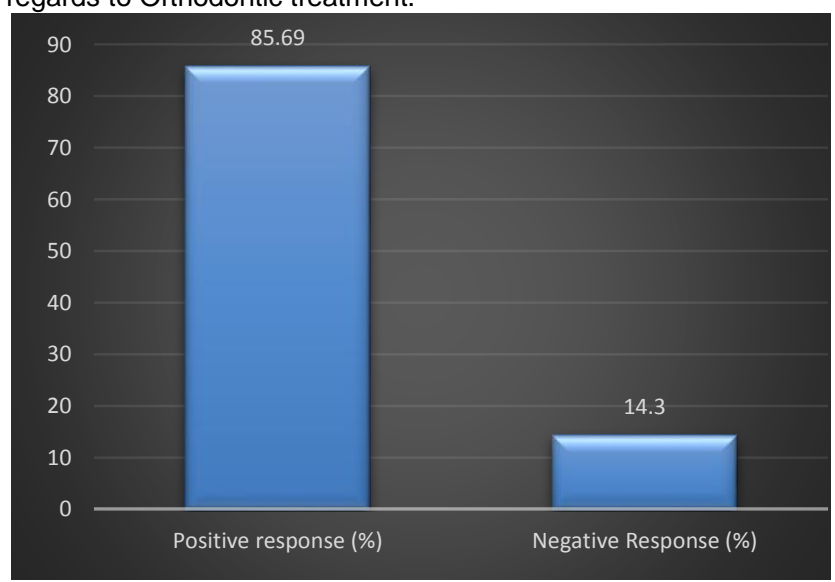

Graph 2: Skills measurement among dental practitioners with regards to Orthodontic treatment.

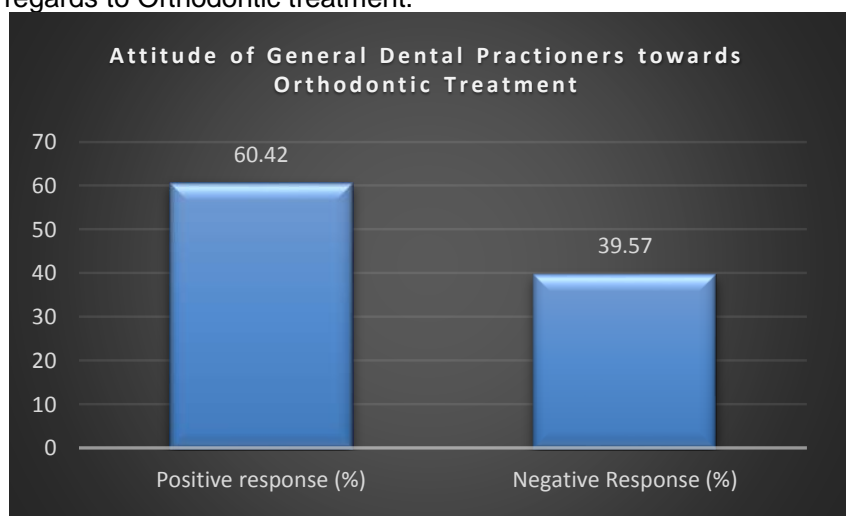

The Graph 1 showed that dental practitioners in Pakistan are were well aware of the Skills used before, during and after the orthodontic treatment. The percentage for the positive responses was $85.69 \%$ whereas the negative response rate was very low which was reported as $14.3 \%$. This showed that dental practitioners in market are orthodontically skilled dental practitioners.

Assessment of the attitude of dental practitioners with regards to orthodontic treatment was also the part of this novel study. The results revealed that $83 \%$ dental practitioners observe dental malocclusion among all the patients whereas $17 \%$ just treat patients' complaints. $69 \%$ practitioners were found to carry out diagnostic orthodontic 
procedures whereas $31 \%$ were not found practicing diagnostic orthodontic procedures. In response of asking about telling the patients to come for orthodontic treatment only after eruption of all permanent teeth, $46 \%$ practitioners response positive whereas $54 \%$ dental practitioners were not found telling their patients to come for orthodontic treatment only after eruption of all permanent teeth. 39\% dental practitioners reported that orthodontic treatment is recommended for patients having periodontal problems whereas $61 \%$ dental practitioners denied to the statement. Moreover, with regards to orthodontic treatment of patients with missing molars, 94\% practitioners reported in favor of the treatment whereas $6 \%$ were against the treatment. Trend of referring patients with complex orthodontic and orthognathic surgical patients to specialists, in both surgical cases and complex cases, positive response rate was $96 \%$ and $84 \%$ respectively which is very high and a good practice.

Graph 2 explained the overall attitude of general dental practitioners is satisfactory towards orthodontic treatment in general patients. The response rate of general practitioners was: $60.42 \%$ positive responses and $39.57 \%$ negative responses were obtained which showed that more than half of general dental practitioners have a positive attitude towards orthodontic treatment guidance to their patients with general complaints.

Table 1: Response rate of Dental practitioners' Knowledge towards orthodontic treatment

\begin{tabular}{|c|c|c|}
\hline Items & +Ve response (\%) & -Ve Response (\%) \\
\hline Are you aware that pathologies must be treated before orthodontic treatment? & 97 & 3 \\
\hline Is orthodontic treatment age specific? & 60 & 40 \\
\hline $\begin{array}{l}\text { Do you believe that straightening the teeth makes better smile, improves speech and oral } \\
\text { hygiene? }\end{array}$ & 97 & 3 \\
\hline Are you aware that paranormal habits have effects on teeth? & 100 & 0 \\
\hline Can you differentiate between skeletal and dental malocclusion? & 97 & 3 \\
\hline Does orthodontic treatment always require extraction? & 4 & 96 \\
\hline Do you know that orthodontic treatment can be helpful in management of TMJ disorders? & 92 & 8 \\
\hline Do you apply space maintainers where required? & 79 & 21 \\
\hline Are you aware of functional appliance therapy? & 96 & 4 \\
\hline $\begin{array}{l}\text { Do you know that functional appliance gives a better result when advised during pre-pubertal } \\
\text { growth spurt? }\end{array}$ & 97 & 3 \\
\hline Are you aware that mini screws can be used for anchorage? & 97 & 3 \\
\hline $\begin{array}{l}\text { Do you consider appropriate molar relationship and interdigitation after orthodontic } \\
\text { treatment? }\end{array}$ & 98 & 2 \\
\hline Should retainers be worn after fixed appliance therapy? & 100 & 0 \\
\hline
\end{tabular}

Table 2: Response rate of Dental practitioners' attitude towards patients with orthodontic treatment

\begin{tabular}{|l|c|c|}
\hline Items & +Ve response (\%) & -Ve Response (\%) \\
\hline $\begin{array}{l}\text { Do you always look for malocclusions on clinical examination when patients report with any } \\
\text { other complaint? }\end{array}$ & 63 & 69 \\
\hline Do you carry out diagnostic orthodontic procedures? & 46 & 31 \\
\hline $\begin{array}{l}\text { Do you tell your patients to come for orthodontic treatment only after eruption of all } \\
\text { permanent teeth? }\end{array}$ & 54 \\
\hline Is orthodontic treatment recommended for patients having periodontal problems? & 39 \\
\hline Do you deny orthodontic treatment for patients having missing molars? & 6 \\
\hline $\begin{array}{l}\text { Surgical cases: Do you refer complex orthodontic and orthognathic surgical patients to } \\
\text { specialists? }\end{array}$ & 96 \\
\hline $\begin{array}{l}\text { Complex cases: Do you refer complex orthodontic and orthognathic surgical patients to } \\
\text { specialists? }\end{array}$ & 84 \\
\hline
\end{tabular}

\section{DISCUSSION}

In this study, knowledge and attitude of general dental practitioners towards orthodontic treatment was evaluated and the results revealed that the knowledge of the general dental practitioners towards orthodontic treatment is above the satisfactory level which is very much suitable and helpful in developing awareness about the hazards of maloculated teeth and promotion of orthodontic treatment awareness among general population?.

Furthermore, it was also found that attitude of general dental practitioners are suitable for the orthodontic treatment promotion while providing the guidance about the orthodontic related issues to the patients. The response percentage was above average which is considered as satisfactory attitude which means that the general practitioners' attitude towards spreading awareness in the general population about the orthodontic treatment is quite better. But there is still a need to improve the attitude of the general practitioners to become a better mediator of spreading awareness of orthodontic treatment among general population?

\section{CONCLUSION}

In conclusion, general dental practitioners depicted higher level of knowledge and a satisfactory level of attitude towards orthodontics which is working as a mediator in spreading orthodontic awareness among general public Implications: This study will motivate the general dental practitioners to be the mediator in spreading the importance of Orthodontic treatment among public as the orthodontic treatment results in improved stomatognathic function, better esthetics and prevention of tissue damage ${ }^{3}$. 
Other important benefits are improved quality of life, increased self-confidence, physical and psychological changes ${ }^{4,5}$. This study will also help the general dental practitioners to improve their attitude towards orthodontic treatment.

Conflict of interest: Nil

\section{REFERENCES}

1. Iqbal A, Glenny A-M. General dental practitioners' knowledge of and attitudes towards evidence based practice. British dental journal. 2002;193(10):587.

2. Shaw W, Addy M, Ray C. Dental and social effects of malocclusion and effectiveness of orthodontic treatment: a review. Community Dentistry and Oral Epidemiology. 1980;8(1):36-45.
3. Feliu JL. Long-term benefits of orthodontic treatment on oral hygiene. American journal of orthodontics. 1982;82(6):473-7.

4. Janzen EK. A balanced smile-a most important treatment objective. American journal of orthodontics. 1977;72(4):359-72.

5. De Oliveira C, Sheiham A. Orthodontic treatment and its impact on oral health-related quality of life in Brazilian adolescents. Journal of orthodontics. 2004;31(1):20-7.

6. Sastri MR, Tanpure VR, Palagi FB, Shinde SK, Ladhe K, Polepalle T. Study of the Knowledge and Attitude about Principles and Practices of Orthodontic Treatment among General Dental Practitioners and Non-orthodontic Specialties. Journal of international oral health: JIOH. 2015;7(3):44.

7. Petersen PE. The World Oral Health Report 2003: continuous improvement of oral health in the 21st century-the approach of the WHO Global Oral Health Programme. Community Dentistry and oral epidemiology. 2003;31:3-24 